\title{
Neurocognitive, Biological and Genetics factors and the Risk of Developing Borderline Intellectual Functioning (BIF) Disease among Kurdish Societies
}

\section{Mohammad Reza Dawoudi*}

Turku University of Applied Sciences, Finland

\begin{abstract}
Differences in intelligence are the most significant factor in explaining levels of social progress and development One measure scientists use to determine differences in intelligence is Intelligence Quotient (IQ), which is derived from standardized tests designed to assess human intelligence. Individuals with IQ scores between 90 and 109 are considered average intelligence and those with scores of 89 to 80 are considered Below Average or Dullness. In this study our analysis of the literature has assessed the level of Kurdish intelligence quotient. The area of Kurdish nation, located in four different countries includes Iran, Iraq, Syria and Turkey. The average IQ of Iranian people is 84, Iraqi people 87, Syrian people 83 and Turkey people is 90 . These numbers came from a work carried out from 2002 to 2006 by Richard Lynn, a British Professor of Psychology, and Tatu Vanhanen, a Finnish Professor of Political Science, who conducted IQ studies in more than 80 countries (IQ Research). Based on this study we estimate the average Kurdish $I Q$ ranges between 83 and 90 . Vanhanen and Lynn argue that IQ and the Wealth of Nations analyses the relation between national IQ scores and measures of economic performance. In this study, we aimed to assess the association between IQ (intelligence quotient) and neurocognitive, biological and genetics factors among Kurdish populations and then we drew inferences about the state of social progress and development of Kurdish societies and genetic characteristics based on a statistical pattern.
\end{abstract}

Keywords: Intelligence quotient (IQ); Borderline intellectual functioning; Neurocognitive; Genetics; Social progress; Kurdish

\section{Introduction}

The term borderline intellectual functioning (BIF) describes a group of people who function on the border between normal intellectual functioning and intellectual disability [1] and it is characterized by heterogeneous cognitive difficulties, with an intelligence quotient (IQ) between 70 and 85 points and a failure to meet the developmental and sociocultural standards for personal independence and social responsibility required in daily life [2]. Borderline Intellectual Functioning is a significant correlate and risk factor for the development of a broad spectrum of neuropsychiatric disorders treated by psychiatrists and, more specifically, is quite common among patients with autistic and psychotic spectrum disorders. Indeed, this condition is closely associated with failure of social expectations, such as school dropouts, social isolation, inadequate affective relationships and with the risk of developing mental illnesses in adolescence or adulthood, e.g. depression, suicidal ideation, self-harm, emotional distress, anxiety and antisocial disorders and, finally, future socio-economic disadvantage [3]. When adults with BIF were (are) compared with the general population, they held lower-skilled jobs and earned less money [4]. Studies investigating the effect of deficits IQ in improving the behavior of people with borderline intellectual functioning have been reported for over one decade. According to the IQ and the Wealth of Nations in 2013, the following four countries are rated as having the low IQ. The average IQ of Iranian people is 84 , Iraqi people 87 , Syrian people 83 and Turkey people is 90. Kurdistan (Homeland of the Kurds) constitutes the marginal areas of these countries [5], therefore we estimate the average Kurdish IQ ranges between 83 and 90 . Based on this study the high prevalence of borderline intellectual functioning among Kurdish people is assumed. In this study, we have attempted to evaluate the role of neurocognitive, biological and genetics factors in the etiology of Borderline Intellectual Functioning (BIF) disease among Kurdish societies. To achieve this goal a review of literature and research studies of relevant papers was carried out.

\section{Literature Review}

Numerous researchers have documented neurocognitive impairment, genetic liability, biological causes such as perinatal difficulties and epigenetic factors such as socioeconomic status and maternal stress all contribute to borderline intellectual functioning [6].

\section{Neurocognitive Factors}

Studies show absence of the arcuate fasciculus is a cause of reduced intelligence [7]. In 2016, Gisella et al. [2] have shown that children with BIF have a deficit in ToM (Theory of Mind) that is strictly connected with their executive functions and meta-representation competences [8]. Furthermore, recent studies have demonstrated a cerebral cortical developmental delay in children with BIF [5].

\section{Biological Factors}

Studies show that CTNND2 is a candidate gene for Borderline Intellectual Functioning (BIF). CTNND2 (Catenin Delta 2) is a Protein Coding gene [9]. This gene encodes an adhesive junction associated protein of the armadillo/beta-catenin superfamily and is implicated in brain and eye development and cancer formation [10]. Diseases associated with CTNND2 include Cri-Du-Chat Syndrome and Pervasive Developmental Disorder [11]. These two diseases are characterized by intellectual disability and delayed development $[12,13]$. According other study in 2012, Hoyer et al. shown that Haploinsufficiency of ARID1B is

*Corresponding author: Mohammad Reza Dawoudi, Turku University of Applied Sciences, Finland, Tel: +358 2215 31; E-mail: m.reza.dawoudi@abo.fi

Received August 26, 2017; Accepted August 29, 2017; Published August 31 2017

Citation: Dawoudi MR (2017) Neurocognitive, Biological and Genetics factors and the Risk of Developing Borderline Intellectual Functioning (BIF) Disease among Kurdish Societies. Int J Neurorehabilitation 4: 286. doi: 10.4172/2376-0281.1000286

Copyright: (c) 2017 Dawoudi MR. This is an open-access article distributed unde the terms of the Creative Commons Attribution License, which permits unrestricted use, distribution, and reproduction in any medium, provided the original author and source are credited. 
a frequent cause of intellectual disability [14]. Haploinsufficiency is a condition that arises when the normal phenotype requires the protein product of both alleles and reduction of $50 \%$ of gene function results in an abnormal phenotype.

\section{Genetic Factors}

Researchers have conducted many studies to look for genes that influence intelligence [15]. Such studies have consistently shown that genetic influence on individual differences in intelligence is substantial [16]. In 2002 Paul Thompson at the University of California, Los Angeles and his team collected DNA samples from more than 21,000 adults to study the links between genetics and some brain disease (brain-drain genes) or variation in a single gene, called HMGA2 that has measurable effect on intelligence [17]. Two years later in 2014 Plomin and et al claimed that two of the most interesting genetic findings are that heritability of intelligence increases throughout the life span and that the same genes affect diverse cognitive abilities [18]. There is evidence that IQ scores are influence by genetic factors. In 2006, Templer et al. [19] have investigated the correlation of both race and skin color in the distribution of mean IQ for 129 countries with primarily indigenous populations. They found that skin color correlated most highly with mean IQ across the Caucasoid countries $(\mathrm{r}=-0.86)$, somewhat less across the Mongoloid countries $(r=-0.66)$ and non-significantly across the Negroid countries $(r=0.06)$. When the Negroid and Caucasoid countries were combined, both race and skin color yielded high correlations with IQ [19]. One year later Caspi et al. have shown that genes may work via the environment to shape the IQ [20]. In other study in 2012, Loo Sandea et al. [21] have conducted a study to determine genetic variants which are associated with human intelligence. Findings indicate that minor alleles are associated with higher intelligence, as seen in singlenucleotide polymorphisms. In 2014, Krapohl et al. [22] concluded that the high heritability of educational achievement reflects many genetically influenced traits, not just intelligence. Simultaneously Plomin and Deary [23] have found that the same genes influence intelligence and social epidemiologists' 'environmental' variables of education, social class, and height can enlighten research in health and social inequalities. In 2016, Kleefstra et al. [24] made the study which helps in the identification of chromatin-modification module associated with EHMT1gene that has been shown to cause intellectual disability (ID) in patients. The protein encoded by EHMT1 gene is a histone methyltransferase that is part of the E2F6 complex, which represses transcription. Defects in this gene are a cause of chromosome $9 \mathrm{q}$ subtelomeric deletion syndrome (9q-syndrome, also known as Kleefstra syndrome) Kleefstra syndrome is characterized by intellectual disability, childhood hypotonia, and distinctive facial features [25].

\section{Materials and Materials}

Physicians are often encouraged to locate answers for their clinical queries via an evidence based literature search approach [26]. Various databases are available for performing literature search [27]. Large databases such as PubMed Health, IEEEXplore, ScienceDirect, PLOS, FINNA, have been used for this study. To obtain clinical information, we review new findings and new theoretical developments in the field of intelligence quotient, neurocognitive, biological and genetics factors associated with borderline intellectual functioning disease.

\section{Discussion}

Future studies are needed to explore the impact of between working memory, sex differences environment, secular and stress effects in aspects of intelligence.

\section{Conclusion}

Our data support the hypothesis that the prevalence of Borderline Intellectual Functioning (BIF) Disease among Kurdish populations has significant impact on state of social progress and development.

\section{Acknowledgement}

The research for this study is financially supported by the Finno Bio Stock Company in Finland.

\section{References}

1. Jannelien W, Frans GZ (2016) It is time to bring borderline intellectual functioning back into the main fold of classification systems. BJ Psych Bull 40: 204-206.

2. Gisella B, Valeria B, Francesca SI, Ilaria C, Davide M, et al. (2016) Socia competence in children with borderline intellectual functioning: Delayed development of theory of mind across all complexity levels. Front Psychol 7 : 1604.

3. Minna P, Timo A, Jukka K, Heikki S, Vesa N (2014) Borderline intellectua functioning: A systematic literature review. Intellect Dev Disabil 52: 419-443.

4. Riamei $L$ (2015) The Kurdish question. Identity, representation and struggle for self-determination. KW Publishers Pvt Ltd.

5. Baglio F, Cabinio M, Ricci C, Baglio G, Lipari S, et al. (2014) Abnorma development of sensory-motor, visual temporal and parahippocampal cortex in children with learning disabilities and borderline intellectual functioning. Front Hum Neurosci 8: 806.

6. Sundaram SK, Sivaswamy L, Makki MI, Behen ME, Chugani H (2008) Absence of arcuate fasciculus in children with global developmental delay of unknown etiology: A diffusion tensor imaging study. J Pediatr 152: 250-255

7. Baglio G, Blasi V, Sangiuliano IF, Castelli I, Massaro D, et al. (2016) Socia competence in children with borderline intellectual functioning: delayed development of theory of mind across all complexity levels. Front Psychol 7 1604.

8. GeneCard Human Gene Database (2017) CTNND2 Gene.

9. NCBI Gene (2017) CTNND2 catenin delta 2 Homo sapiens (human).

10. GeneCard Human Gene Database (2017) CTNND2 Gene.

11. NIH \& GARD (2017) Cri du chat syndrome.

12. Benaroch $\mathrm{R}$ (2016) What are pervasive developmental disorders? WebMD.

13. Hoyer J, Popp B, Ekici AB, Endele S, Zweier C, et al. (2012) Haploinsufficiency of ARID1B, a member of the SWI/SNF-A chromatin-remodeling complex, is a frequent cause of intellectual disability. Am J Hum Gen 90: 565.

14. Genetics Home Reference (2017) Genetics and human traits.

15. Plomin R, Deary IJ (2015) Genetics and intelligence differences: Five special findings. Mol Psychiatry 20: 98-108.

16. Coghlan A (2012) Single gene affects IQ - but only just (genetic influences on brain diseases). New Scientist 214: 14.

17. Plomin R, Spinath FM (2004) Intelligence: Genetics, genes and genomics. J Pers Soc Psychol 86: 112.

18. Templer DI, Arikawa H (2006) Association of race and color with mean IQ across nations. Psychol Rep 99: 191.

19. Caspi A, Williams B, Kim-Cohen J, Craig IW, Milne BJ, et al. (1915) Moderation of breastfeeding effects on the IQ by genetic variation in fatty acid metabolism. Proc Natl Acad Sci USA 104: 18860.

20. Loo SK, Shtir C, Doyle AE, Mick E, Mcgough JJ (2012) Genome-wide association study of intelligence: Additive effects of novel brain expressed genes. J Am Acad Child Adolesc Psychiatry 51: 432.

21. Krapohl E, Rimfeld K, Shakeshaft NG, Trzaskowski M, Mcmillan A, et al. (2014) The high heritability of educational achievement reflects many genetically influenced traits, not just intelligence. Proc Natl Acad Sci USA 111: 15273.

22. Plomin R, Deary IJ (2015) Genetics and intelligence differences: Five special findings. Mol Psychiatry 20: 98-108. 
Citation: Dawoudi MR (2017) Neurocognitive, Biological and Genetics factors and the Risk of Developing Borderline Intellectual Functioning (BIF) Disease among Kurdish Societies. Int J Neurorehabilitation 4: 286. doi: 10.4172/2376-0281.1000286

23. Kleefstra T, Clark RD, Kramer JM, Devriendt K, Neveling K, et al. (2012) Disruption of a EHMT1-associated chromatin-modification module causes intellectual disability. Am J Hum Genet 91: 73.

24. Tjitske K, Willy MN, Helger GY (2015) Kleefstra syndrome synonyms: 9q subtelomeric deletion syndrome, 9q34.3 microdeletion syndrome, 9qSTDS. Gene Reviews.
25. Gah JH, Su ML, Chirk JN, Ranita HS, Paul G (2016) Development of a search strategy for an evidence based retrieval service. PLoS.

26. Anju G, Hanish K, Ira D (2016) Literature search for research planning and identification of research problem. Indian J Anaesth 60: 635-639.

27. Richard EN, Joshua A, Clancy B, William D, James F, et al. (2012) Intelligence new findings and theoretical developments. Am Psychol Assoc 67: 130-159. 